\title{
EL AMOR EN LA NOVELÍSTICA CANSINIANA
}

JosÉ FranCISCO RODRÍGUEZ RODRÍGUEZ

UNED

chikki000@hotmail.com

\section{RESUMEN}

A través del conjunto que forman las novelas cortas de Rafael Cansinos, los lectores son testigos de un nuevo lenguaje sexual, basado en el mito de la mujer. El modelo de feminidad tradicional es reconocido por el conjunto de la sociedad. En contraposición, el Modernismo es un potente actor que cambiará los convencionalismos del arte. Las relaciones, en este caso, se concentran en aspectos como el sexo y la muerte, la pasión y la razón, la modernidad y la evolución social. La literatura de Rafael Cansinos es un importante modelo de la capacidad de la acción creativa en el largo proceso de transformación de la historia.

Palabras Clave: mito de la feminidad, lenguaje sexual, transformación social, instrumento artístico, novela corta.

\section{Abstract}

Through the group constituted by Rafael Cansinos short novels, readers are witnesses of a new sexual language, based on woman myth. Traditional female model is recognized by the whole social structure. Facing that Modernism is a powerful player which will change all the art conventions. The relationships, in that case, are focused in odd aspects like sex and death, passion and reason, modernity and social evolution. Rafael Cansinos literature is an important paradigm of the competence of creative action in the large process of history transformation.

KEYWORDS: woman myth, sexual language, social evolution, artistical instrument, short novel. 


\section{UNA LEVE INTRODUCCIÓN}

La no suficientemente estudiada novelística cansiniana ofrece un enorme espacio de indagación sobre la palabra literaria española, en un período en el que confluye con una crisis de valores de los usos y costumbres del arte, así como de su integridad ética y su relación con una sociedad en profundo proceso de transformación.

Este texto, que es un extracto de la tesis doctoral titulada Rafael Cansinos Assens. La renovación del lenguaje de la novela, se inserta en el trabajo de investigación de esa realidad artística, de la que manan numerosos rasgos que singularizarán la nueva novela del siglo XX. Como todo estudio, supone una suerte de variable determinista que, de alguna manera, va creando pequeños surcos en una tierra que ha de ser labrada por el conjunto de la comunidad científica e intelectual.

En ese marco de reflexión, el conjunto novelístico y narrativo del autor sevillano conforma un grupo especialmente significativo de gran exclusividad. Se trata de una materia literaria individualizada y, a la vez, de un ejercicio estilístico y estético de sólida intertextualidad, donde las obras parecen estar concebidas como un todo, hermanadas hasta el punto de formar parte de una misma concepción. Esto hace que, a la manera de una semiótica particular, Cansinos Assens construya un foco novelístico de interesante singladura, en el que participan juegos abigarrados de haces expresivos. Entre esos elementos de edificación arquitectónica significativa está el personaje femenino.

Ofrecemos al lector, pues, la posibilidad de indagar, al menos sea superficialmente, en este particular aspecto: la mujer es un mito, es un símbolo, es una palabra heredada que transmite su conocimiento a través del tiempo y que posee, aparte de su etimología cultural y escénica, un importante sedimento informativo, producto de su interacción con la sociedad. Hay una significación funcional, que deriva de su papel en el conjunto, y un amalgamamiento de elementos estéticos que, en torno a su figura, representan varias realidades entremezcladas, unas veces innatas y, otras, aprehendidas.

El papel de la mujer y lo que en ella confluye (el intervencionismo de la fe programada y su metalenguaje, el rol sexual, la maternidad, la herencia del amor literario, los convencionalismos o su nuevo lugar como símbolo del modernismo, etc.) sirven de gozne a nuestro autor en la construcción de un nuevo lenguaje que se inserta en la filosofía primariamente modernista, aquella en la que la libertad estética exige una relación intensa e individualizada con el poder que construye las civilizaciones y las sociedades humanas.

No se trata de hacer un ejercicio de profundización en el elemento femenino dentro del lenguaje literario, o de reivindicar un papel de la mujer que, desde el punto de vista funcional y dinámico se ha verificado como incontestable, y cada vez más presente, sino de echar la vista atrás y reflexionar sobre cómo un autor proyectado en el futuro, como Cansinos Assens, utiliza ciertos elementos heredados para transformar la tradición en un puente comunicativo hacia un mundo en permanente construcción, que ansía de sí y de su ser constantemente.

Es en su inconformismo estético en el que descubre modos de transformación, aplicaciones de signos que se elevan desde un titubeo (solo aparente) hacia la construcción de un lenguaje, que sirve de motorización codificada del compromiso que los artistas han colocado al frente de su filosofía. 
En conclusión, este texto no es un ejercicio comparativo de un aspecto tan particular de la literatura moderna, especialmente, sino una aproximación a uno de los símbolos del arte cansiniano que, en el marco de su obra novelística, desarrolla los aspectos esenciales de un género en constante crisis de valores. Este símbolo, junto al judaísmo impostado, la profundización poética, el costumbrismo desabrido y la normalización de un yo exacerbado conforman, entre otros, elementos que, en su conjunto, demuestran la aportación de la obra de este importante autor sevillano a la conexión entre la novela española y la moderna novela europea y norteamericana: algo que resultará ya evidente en Tiempo de silencio, de Luis Martín-Santos. Recuperando estos aspectos, desdeñados por el tiempo largamente, descubrimos un sendero que creíamos perdido, lo que nos permite abrir los ojos en otras direcciones.

\section{LA MUJER COMO SÍMBOLO LITERARIO}

En la literatura de Rafael Cansinos Assens puede que la mujer sea un cosmos en sí mismo del que participan todos los seres, pues no existen mujeres más allá de una sola mujer, que es la que representa el ideal que completa la existencia. Y, en todo caso, nuestro autor no hace sino emparentarse con una nueva generación que pone en primera línea un tema considerado argumento complementario para la novela del folletín, o simplemente un aspecto costumbrista del arte decimonónico. En ocasiones, la novela cansiniana usa del amor con un regusto medieval o romántico, al tiempo que visualiza aspectos extremadamente oscuros de las relaciones humanas, lo que no deja de parecer un sarcasmo artístico. En todo ello vemos una especial predisposición del creador a explicitar este aspecto como uno de los más importantes de su obra. Sobre él, de hecho, construye una gama de personajes y de relaciones que completan una tipología singular y muy característica de su configuración literaria. De todos modos, es evidente que su visión de la feminidad viene condicionada por una educación que, contextualmente, tiene ciertos visos de tradicionalismo. En ese sentido, para conformar el mito de la mujer, donde se contienen los aspectos de la sexualidad, la posesión o la maternidad, se necesita una justificación que sublime el perfil cotidiano de ese insuficiente papel que la sociedad le asigna. La mujer, por todo ello, es vista desde el autor-hombre como un ser distante y desconocido que implica una ignorancia sobre su auténtica condición. Así lo ve, también, Luis Miguel Vicente García.

(...) como en el resto de su obra en prosa, Cansinos Assens es más un cronista de la realidad que un imaginativo. Cuenta lo que vive, y habla de la condición femenina desde las luces y las sombras que le inspiran las mujeres que conoce (las de su familia, las de los burdeles, las escritoras, las de la literatura...) condoliéndose de lo que considera tal vez el aspecto más triste de la mujer de su tiempo: su capacidad para suplicar, encorvarse y mostrarse como víctima y como el ser más desgraciado del mundo. Al tiempo que, en el otro extremo, resplandece como el ser de alegría más intensa, de belleza irresistible. Es una naturaleza doble y contradictoria que Cansinos percibe como misterio (...). (Vicente García: 51)

Empero, es complicado poder justificar esta apreciación al completo una vez que se han leído los textos. Esa realidad de la literatura de Rafael Cansinos no puede ser la realidad lógica que parece sugerir Vicente García que está detallada allí. Toda vez que su visión de la feminidad sí que corresponde con la tipología superficial de los caracteres usados, entonces ¿dónde 
está la sensible diferencia percibida? En el hecho de que la mujer constituye un emblema que va mucho más allá de toda su limitación social o su maniquea debilidad histórica. Sus maneras no están alejadas del modelo de mujer que el lector conoce o que ha tipificado en su estereotipo cultural, aunque en la nueva ideología creativa la mujer es un eje central, un núcleo activo de propuestas y referencias sociales e intelectuales, de las que el hombre se considera deudor y no origen. De hecho, las mujeres de las novelas cansinianas, aun en su más profunda desgracia, suponen un modelo de equiparación con el hombre, en su soledad o retiro, y, en el resto de los casos, un objeto anhelado situado en un plano superior y que, en la práctica, más allá del símbolo, gozan de un estatus íntimamente reconocido en el círculo más cercano. La socialización de sus ideas emancipadas, por lo tanto, ponen a la mujer en un plano de opinión distinto al que su aspecto exterior denota. Es una manera de adaptación del casticismo que, por el tamiz de los modernismos, llega hasta la última expresión poética del concepto más hipertrofiado de feminidad, apoyándose en las bondades del tópico literario a través de la historia. Es por ello que, como aprecia Conde Guerri, la realidad se extrema hasta que se convierte en alegoría de ella misma, en una deformación intencionada que transformará la desgracia general en un marco teatral de discusión, y la mujer en un mito de la modernidad.

En su planteamiento partirá de situaciones amorosas vinculadas a un acendrado clima de degradación, factibles de engendrar en su voluntario paroxismo la nueva ideología propiciada por la vanguardia. Es decir, empleará de forma sistemática la consagración del cliché melodramático finisecular, entendida como vía depurativa y creadora de una nueva estética. Todo sentimiento en sus novelas es desbordado, carente de límite racional y así se convierte en metafórico, ofreciéndose en consecuencia a perspectivas más amplias dentro de una alegoría del amor absoluto. (Conde Guerri: 29-30)

Sería interesante entender que buena parte de su exposición crítica de la sociedad, orientada hacia el erotismo y la degradación de los sentimientos, así como a los comportamientos prohibidos y los pensamientos excéntricos, suponen, en el caso de la visión femenina, una manera de superar la barrera de los prejuicios adquiridos culturalmente. Dado que un hombre de su época posee un nulo conocimiento de la condición de la mujer en su íntima esencialidad, la elasticidad del lirismo le permite llegar a los recónditos aspectos de una diferente socialización, basada en una mayor libertad y participación en los ámbitos de las relaciones interpersonales. Esto supone una revolución considerable, entendida la mujer, por vez primera, como un ente responsable de su propio devenir, y no como alguien dependiente sólo por razón de su sexo. Evidentemente, Cansinos Assens no es un autor de visión moderna en este sentido, puesto que su modelo de mujer es bastante convencional. Pero, a juzgar por su utilización en el ámbito literario, crea de ella un mito que ofrece una oportunidad de superación de ciertos maniqueísmos seculares.

Claro que escribe en una época en que el punto de vista masculino prepondera de un modo absoluto y las mujeres no han empezado a hablar con libertad de cómo sienten su identidad y sexualidad (...) Todavía ve que el feminismo, como también lo sintió Pardo Bazán, suponía desarrollar básicamente posturas y destrezas masculinas -la escritura entre ellas- y renunciar a la posición de servidumbre que de un modo tan terriblemente unánime se ha adjudicado a la mujer en las diversas civilizaciones (...). (Vicente García: 51)

No obstante, Vicente García insiste en considerar que buena parte de la singularidad de la mujer, como ente social, reside en su forma de afrontar la soledad y la desgracia, que 
parecen inherentes a su rol. Del mismo modo, Pardo Bazán, al insistir en el perfil de dominación que la trama de sus novelas impone a sus personajes femeninos, no hace sino incidir en las consecuencias negativas que el modelo social tradicional ejerce sobre las mismas, inoculando en el metalenguaje histórico una conciencia emancipadora: aquella que, a través de la reflexión y el objeto artístico, erosiona los postulados de la casta. El hecho de que la mujer sea una excluida desde el primer momento de su presencia, ya que se encuentra ante el callejón sin salida que no le ofrece sino el sometimiento a unas injustas reglas o la expulsión, resulta una oportunidad única para la consolidación de una tipología literaria que Cansinos sabrá aprovechar muy bien. Su visión del nuevo héroe modernista -tan trágico como el romántico pero más práctico en su acción final- casa a la perfección con esa condición femenina que, finalmente, supondrá el punto de referencia ideal para el hombre, quien debe aprender a superar toda miseria y a renovarse. La mujer, como un ave Fénix, permanecerá en un nivel inalcanzable de fortaleza, desechando, así, todo lo que la rodea y saliendo victoriosa. Esa percepción de la feminidad como de una fuerza de la naturaleza, no disminuye un ápice su adhesión a la idea de belleza tradicional y, de hecho, como en el caso del personaje de Última, por ejemplo, consigue aportarle el matiz de modernidad que la constituye en un emblema de los nuevos tiempos.

Porque la mujer, acostumbrada a ser el último eslabón de la cadena, convive con un sufrimiento existencial y un abandono que ha transformado en potencialidad y en acción vital; mientras que el hombre, habituado a ser el centro de las cosas, no soporta su exclusión social, viéndose condenado a la muerte. Esa relación entre la nada muerta y la nada viva, representada por la mujer, es el morboso emparejamiento que Cansinos lleva a efecto en su teoría del sexo. Sexo y muerte, veremos, son dos caras de la misma moneda.

La combinación de elementos que se concentran en el nuevo símbolo femenino es tal que no acaba de ser identificada por la cultura vernácula. Existen rasgos que matizan modelos anteriores, hasta el punto de que se producen confluencias que chocan con la visión tradicional y que dificultan, de entrada, la recepción del mensaje. La entrada de conceptos de la cultura oriental o la defenestración de ciertos valores del catolicismo más acendrado sirven, por un lado, para modificar los puntos de vista del lector, con el fin de superar los límites que marca su propia educación y sus prejuicios y, por otro, para liberar al mito del corsé de la herencia cultural, muy férreo en este caso. De este modo, el mito es capaz de transformarse, permaneciendo no obstante como argamasa de una realidad que se ha tornado más compleja y que integra muchas más dimensiones. Una de las más complicadas de integrar es la que afirma que la mujer, más allá de toda concesión a su papel sexual o a su rol familiar, es un ser en plenitud que exige su espacio. Para autores de su época, como el nuestro, el efecto «rebote" le lleva a concebir mujeres literarias, en el sentido figurado, es decir, modelos que rechazan la realidad preconcebida y su papel en ella, que llevan hasta el extremo su exigencia, colocándose en un plano inalcanzable para el hombre. Sobre todo se trata del reconocimiento de una condición cotidiana: en una sociedad claramente dominada por los hombres y donde las mujeres juegan un papel secundario, éstas, sin embargo, son las que condicionan buena parte de las acciones que se realizan y, en la sombra, dominan el terreno de la sentimentalidad y la motivación. Así, los personajes varones de sus obras no sienten reparo alguno en admitir que necesitan a la mujer para completarse, que son dependientes y que no hay otra razón de vida que la de entregarse al amor femenino. Si a esto le añadimos que la libertad sexual 
proviene de una visión de la mujer, mucho más preclara, y que el sentido de la santidad y el recogimiento parecen pertenecerles de manera natural, la superioridad moral y sentimental de la mujer es evidente. Por eso a ella le corresponde atesorar los rasgos del mito y sólo ella puede liderar los nuevos tiempos, ya que es la superviviente de todos los males de la historia. Al no existir un precedente aceptado en nuestra cultura que sea capaz de aglutinar tales contradicciones, Cansinos acude a su afinidad oriental, es decir su adscripción de los paradigmas del símbolo femenino que contrastan, en un plano de equilibrio de poderes, con el rol del hombre, para modelar la estética del símbolo, en todas aquellas manifestaciones de la literatura folclórica que impregnan lo que, grosso modo, se hacía llamar el Oriente, y que engloba aspectos de las filosofías árabe o hebrea, en particular.

Es a partir de estos conceptos — misericordia, generosidad - donde Cansinos encuentra el punto de articulación que le enraíza con la tradición oriental. (...) Resultaría incontrolable el número de ocasiones que el autor define el cuerpo y la actividad sexual de la mujer a modo de un fruto o de una ofrenda (...) (Conde Guerri: 31)

También nuestro autor se enfrenta a esta idea desde el ejercicio de la crítica, creando una distancia aséptica de análisis literario, como si él mismo no se viese afectado por tal circunstancia, o como si quisiera dar a entender que su visión de la mujer no nace de su propia soledad vital, algo que parece, a todas luces, poco probable. En todo caso, siempre hace suya la identificación de los personajes del texto y la mujer, protagonista del poema, es escrutada retóricamente como si contuviese un misterio aún no definido.

¿Qué suerte de amor es esa que no despierta celos? ¿O es que desvarías, mujer apasionada? (Cansinos Assens, 1930: 23)

Esta relación entre arte y deseo carnal es un motivo común de la literatura. El artista, en su motivación íntima de desarrollo de la idea, expone, en realidad, una atracción fatal hacia la expresión carnal de la misma. La idea ha de ser realizada, cosificada para el placer de su apreciación, corporeizada. De tal manera que la creatividad es una forma de dar cuerpo a las pasiones internas del artista, del mismo modo que la acción sexual es una identificación de las pulsiones corporales en el objeto sexual deseado: sea mujer u hombre. Por ello, y ya que la historia ha concebido como «normal» el deseo heterosexual y así lo ha estereotipado, la mujer se convierte en objeto, en cuerpo artístico que contiene en sí los rasgos de una idea creativa, poética, lírica y plena de belleza. Mito sexual es, por lo tanto, mito de la creación.

En realidad, Cansinos Assens hace suyos muchos de los postulados del pensador renacentista, que ya observó en la mujer una oportunidad de renovación de los idearios medievales. Curiosamente, al poner al hombre en el centro del huracán filosófico y vital, la figura de la mujer resalta por encima del conjunto y se vuelve imprescindible, reconociendo implícitamente la dependencia natural del individuo de su parte femenina, que es consustancial a él y que, liberada, produce una multiplicidad de la realidad notablemente más enriquecedora y completa. Así, los viejos valores, concentrados en el papel social de la mujer y en la unidad familiar así concebida, quedan anulados o, al menos, solapados por la irrupción de un nuevo ser que pide protagonismo y que, sin el apoyo de la historia, consigue, partiendo de cero, colocarse en un plano de interés superior. Por consiguiente, la sexualidad puede actuar como vehículo de la revolución artística. El sexo es un elemento definidor del perfil humano, social 
en una comunidad con principios morales. La naturaleza acaba convertida en un bien de cambio ideológico y de dichos principios.

(...) la rosa de carne, la última espina de su virginidad. (Cansinos Assens, 2011d: 80)

El erotismo es, por consiguiente, la manifestación de una serie de intenciones implícitas en el atractivo intelectual del objeto deseado, experimentado a través del físico. No se trata únicamente de un rasgo animal instintivo sino, también, de la seducción que ejerce el conocimiento y que resulta avasalladora. El secreto, el misterio que esconde el cuerpo desconocido, nos descubre sensaciones que creíamos ignotas. En el personaje de Sophy (objeto de La leyenda de Sophy y citada en otros textos), por ejemplo, su sofisticación es altamente sexual. De hecho, ella viene representada como la maestra de la vida de alguien que no ha conocido aún el sexo, y que se siente intimidado en su presencia. Lo que son unas clases de idiomas se transforma en una revelación de secretos vitales. Y es que el sexo, en realidad, consiste en un autodescubrimiento del ser, lo que implica una reflexión intelectual canalizada por el deseo físico. En el caso de la prostituta, paradigma del escalón inferior en la feminidad —y en la sociedad misma-, los beneficios obtenidos y su reconocimiento entre los admiradores, en algunos casos, superan las expectativas de algunos de los artistas, envidiosos de tanta acumulación de belleza. Esta paradoja literaria supone una reivindicación de la naturaleza del arte, que no es una impostura ni una pose, sino un arrebato de instinto vital y superación de las dificultades.

(...) aquellos hombres que la amaban a ella y no amaban nuestros versos (...) (Cansinos Assens, 1923b: 12)

De hecho, el hombre inteligente busca todo aquello que no se parezca a una mujer resignada, necesita de ella el impulso que le obligue a avanzar y que le recuerde su compromiso con la vida, que no es otro que su negación de toda renuncia y su valorización de sí mismo.

(...) rejuveneciéndose en aquella errabundez de célibe (...) renovó las emociones de su bohemia artística (...) (Cansinos Assens, 1924: 1)

\section{MATERNIDAD Y CONCIENCIA}

Independientemente de lo que la mujer ha de significar a ojos del hombre, existen una serie de rasgos asociados a ella que están impresos en el mapa de la historia, pero que pueden ser vistos desde una óptica mucho más independiente y menos atávica. La maternidad es una función social, humana y casi mística de la mujer por la cual se la venera y se la respeta, pero también se la esclaviza y se la coloca en posición de víctima de un interesado conductismo. Resulta cómoda la actitud social e histórica que alaba la natalidad mientras descarga la responsabilidad de la misma sobre quien la padece, la sufre y la experimenta aunque, también, la goza y la mima. En este complejo orden de cosas y de sentimientos, la maternidad es un mito de la historia, una fábula en la que la mujer es el recipiente que contiene el principio del universo - ver el famoso cuadro El origen del mundo de Gustav Courbet—y que está relacionada con una despersonalización de la fémina como individuo, pues su función sagrada le obliga a renunciar a todo lo demás, incluso a ella misma. El mundo, pues, comenzó siendo 
materno. Para lo cual se busca un encaje de dicha maternidad, un espacio regulado por las leyes del hombre que permita la adecuación del sagrado sacrificio de la mujer, en aras de una expansión de la humanidad. El matrimonio es el receptáculo de la maternidad y ambos se presentan como sacrificios dolorosos de la mujer con un fin social.

(...) el blanco velo irrevocable, como una cándida mortaja. (...) un destino consagrado a la maternidad heroica. (Cansinos Assens, 2011d: 26)

Claro está que la maternidad está asociada con un sentimiento anímico esencial en el bienestar de la mujer, en su completitud, y corresponde también a un alto grado de su libertad como ser humano cuya esencialidad es singular. En consecuencia, la castración más innoble y dolorosa es la que separa a la mujer de la maternidad que, en el caso de la maternidad trasladada a la figura del hermano, que es una trasposición contra natura, está adoptada pero cuya conciencia no deja de ser completa. Los ejemplos de la mujer del protagonista que trata a su hermano como a un hijo, llenando así su propio vacío maternal, son variados en la novelística del autor sevillano.

Y entonces se acordará de mí, de su hermana, de la única criatura que lo quiso de verdad en este mundo, de la hermana mayor, que para él fue una madre y le lavó cuando niño y le veló el sueño de huérfano y de la que hizo menosprecio pro complacer a una mujer extraña. (Cansinos Assens, 2011d: 161)

Por lo tanto, la mujer que se completa a través de la maternidad, que cierra su ciclo existencial tentada por el instinto que brota de su ser, llega a la confirmación de su persona y a rozar cierta forma de felicidad que transmite, como un don, al hombre, al que relaciona con dicho estado de bienestar y plenitud. El matrimonio, así concebido, carga de positividad la imagen costumbrista de la unidad familiar, como elemento vertebrador de la España casticista. Hay bastante de hierático en la contemplación de la mujer madre como un objeto de pureza, donde el sexo no tiene atisbo de mácula, ya que sólo se ha dado con un motivo sacro y parece, casi, no haberse producido. Por eso la madre bien puede ser confundida con una virgen.

-Él, enternecido por la acongojada belleza de su rostro, que se torna maternal a la sola evocación de los ahijados, maravillado de la belleza con que la maternidad figurada dota a la esposa estéril, presintiendo qué distinto surco, más ancho y profundo, pudo trazar en su vida el advenimiento de un pequeño y con cuánta mayor plenitud se hubieran amado los dos, murmura esta queja indigente, tan lamentable en la tierra florida — ¿Por qué no habremos tenido un hijo? (Cansinos Assens, 2011d: 204)

También existe un aspecto varonil de la maternidad no asociado al matrimonio sino a la sexualidad, y que poco tiene que ver con el deseo de construcción familiar, sino con el instinto hedonista del hombre. La maternidad puede ser, también, un motivo de rechazo por parte del amado, que la relaciona con la fealdad, con la deformidad. La belleza intacta de la mujer se ve consumida por el esfuerzo que supone la concepción y su posición dominante se ve relegada a un segundo plano, por lo que el hijo es un competidor, más que un ser querido y deseado, digno de protección. Entonces es cuando la natalidad acaba identificándose con una traición al amor, que sólo redimía al hombre a través del placer de la carne y los sentidos, incompatibles con la crianza de un niño. El parto es un desgarro incurable del cuerpo de la mujer y una herida abierta en el deseo del hombre. 
Así había vivido ella, bajo el ceño constante del amado, desde que se abrieron las fuentes de su fecundidad (...) (Cansinos Assens, 2011d: 122)

Es, por tanto, la maternidad una confluencia de sentidos antagónicos dentro de su semiótica literaria. El signo, en sí, está identificado en la cultura popular y, en especial, en la obra de nuestro autor, con el pecho de la mujer. Dicho signo es una constante en su concepción de la maternidad y representa, además, la forma evidente de la sexualidad femenina, condensando muchas de las dimensiones que aglutina su poliédrica significación. Por lo cual, por ejemplo, puede representar el espacio de refugio del hombre, que fuera del entorno de su inocencia se encuentra absolutamente desamparado, a la intemperie.

Y temblaba su seno maternal en la congoja de su llanto. (Cansinos Assens, 2011d: 10)

Pero también representa la paz, la estabilidad, el símbolo de la fertilidad que está asociado a la vida y a la riqueza de los pueblos, prosperidad de la familia y suerte: fuente dadora de vida y de consuelo. La forma geométrica del seno es también motivo de atracción estética y de ironía literaria, asuntos muy propios del modernismo. Su redondez es una llamada al desorden lírico del comportamiento humano, a la irracionalidad festiva, al disfrute de los sentidos que evoquen una humanidad liberada de su corsé positivista. En el pecho femenino encontramos, asimismo, un reflejo de la personalidad, un rostro vivo, un objeto que comunica y que semantiza cosas, cuya ausencia es una alienación del ser mismo de la mujer.

(...) su rígido pecho, consumido en la aridez (...) (Cansinos Assens, 2011d: 37)

(...) a ella, que se presentaba pobre y lisa, enlutada como una viuda. (Cansinos Assens, 2011d: 84)

Lo explicitado en la obra de Cansinos, a lo largo de todo el conjunto de su novelística, indica que el signo femenino sólo tiene encaje en el ámbito sexual o en el maternal, lo que implica una conexión del ser en su origen. Esto puede ser tenido en cuenta como una limitación tradicionalista de la mujer como objeto literario, toda vez que el modernismo también tiene una fuerte carga de profundidad de tradicionalismo, sobre todo en sus comienzos. Dicho esto, el hecho de que el autor expanda los valores de la feminidad hacia el mito de los nuevos tiempos concede nuevos principios al objeto y a los actos relacionados con el mismo. Pero los rasgos costumbristas permanecen.

Y por este nombre de madrina no es ella definitivamente una mujer de senos desamparados. (Cansinos Assens, 2011d: 93)

\section{LA RELIGIÓN EN EL ÁMBITO DE LAS COSTUMBRES Y EL LENGUAJE}

Esa mezcla de liturgia religiosa y actividad sexual es un discurso apreciado y desarrollado en la obra de Cansinos, desde los postulados de una visión artística ideológicamente crítica. La religión es una herramienta cultural que forma parte de la educación materna de los hombres y una herencia de la historia que contiene, en el caso del judaísmo, elementos desencadenantes del desarrollo lingüístico — aunque suponemos que también forma parte de la cultura católica y de su simbolismo-. En tal caso, la religión contiene conocimientos y 
experiencias acumuladas por el hombre que se revisten de creatividad, de misticismo, de irracionalidad y que alcanzan el ámbito de la poesía. Más allá de la fe, la religión es un poema de la vida que contiene todos los ingredientes de las relaciones del hombre con el hombre, pero maquillados por la moralidad que trata de constreñirlos y empaquetarlos en su particular «caja de Pandora». La literatura cansiniana, en su discurso crítico, libera las fuerzas contenidas en la cultura religiosa, asociándolas con lo más degradante e innato de la naturaleza humana. Con lo que Cansinos no hace sino reivindicar una mirada influenciada por el prisma de la filosofía oriental, donde el sexo es visto como un acto sagrado y una posibilidad de conexión íntima entre la divinidad y su creación palpitante. En esta crepitación de las partes del hombre, se manifiesta una vieja consideración sobre el equilibro del ser y la nada, la mujer y el hombre, la teoría de las mitades que compone el acto de integración de los sexos, incompletos por sí mismos. El sexo es, una vez más, el acto de llenado de un vacío existencial que se sabe presente y que requiere una compensación. En la mística judía este mensaje permanece fijado y visible y Cansinos lo hace suyo. Por lo que toda morbidez asociada a la santidad no es sino una valoración litúrgica de la religiosidad implícita en el sexo.

¿Qué nostalgia de raza, qué afrenta secular, qué dolores arcanos lloran discretamente bajo la alegoría de estas coplas eróticas prestándoles sus solemnes acentos religiosos? (Cansinos Assens, 1936: 17)

El matrimonio consagra una unión inseparable, por lo que el sexo concebido dentro del mismo no es sexo, es una sacra manifestación del amor de Dios. En el judaísmo, la mujer también se erige en templo y símbolo de la búsqueda.

Alegría sensual y mística, pues que culmina en esa idea pascual, propia del ciclo religioso judaico.

El vientre de la esposa es como un arca de la alianza, como la mesa de un pascual convite en que el hombre puede celebrar desde luego el rito. (Cansinos Assens, 1930: 230)

Porque, en realidad, la religión consagra el símbolo femenino como vía de salvación. Luego, también, el amor no es sólo un deseo formidable que conecta con la figura espiritual, con el gran creador, sino que da forma al sentimiento de raza, que en él pervive, y que mantiene la pureza de tal sensibilidad. Porque, de cara al ordenamiento de la especie, difícilmente puede servir un sentimiento que no es transmisor de una autoridad, de una herencia en forma de tradición, forma en que la liturgia se apodera de la espontaneidad y congela en un frasco de ordenación moral lo que el nuevo arte considera como una manifestación libre de la intimidad del individuo.

Mire usted: si alguna vez he de dar mi corazón a una virgen, venciendo el instinto pánico que me impulsa a amarlo todo, no habrá de ser a una mujercita frívola de nuestra tierra. Elegiré una criatura de la raza doliente; una criatura que haya sufrido, que haya heredado de una madre triste un corazón grave y profundo. Vivo en la esperanza de ese encuentro. (Cansinos Assens, 1916: 197)

Eso da lugar a dos realidades: la mujer que se observa en la liturgia, que es un símbolo literaturizado de la mujer social. Aquellos que consideran que los esfuerzos de los modernismos por cambiar la sociedad y modernizar las viejas tradiciones, liberando al hombre de sus 
propios corsés, critican la limitada actuación en el campo del arte y las letras, recordándonos su futilidad, su esteticismo y su nulo poder de influencia, han de echar la vista atrás hacia lo que han significado para las sociedades, históricamente, los mitos literarios contenidos en los textos sagrados, que con su elevación del mito de la virginidad, por ejemplo, han conseguido estructurar al hombre y sus relaciones sociales, en una clara intervención a través de la palabra heredada, que es como decir el poema heredado. De la misma manera, la literatura cansiniana transforma el campo de la liturgia, consagrando el sexo, como tal acción y no relacionada con la estructura social, y logra transmitir una idea de religiosidad que diviniza al hombre, a su naturaleza, y no su negación, como las religiones tradicionales hacen.

El mundo está necesitado de esas sacras orgías en que se purifica el pecado, y se eleva a la solemnidad y al arte de un culto lo que de otro modo es un episodio no siempre bello. (Cansinos Assens, 1922c: 459)

Por lo tanto, en la literatura de Rafael Cansinos Assens el sexo se sugiere, con toda su potencialidad activa, y se siente en su magnitud, pero, como en el caso del símbolo de la serpiente, sigue siendo tachado en su superficialidad, con lo que se cumple un cierto compromiso con las formas sociales establecidas.

Ofrecíase así a la tentación y vagaba hasta muy tarde por las encrucijadas, llenas de silbos y siseos, como un bosquecillo en que tuvieran sus camadas las serpientes. (Cansinos Assens, 2011c: 76)

Siendo la mujer un vehículo de salvación en la liturgia amorosa, el descubrimiento de la sexualidad, aunque influye profundamente en el sentido vital del hombre, no altera el sentido de sacralidad que acaba asociado al objeto femenino. Entendamos, de todos modos, que por muy sagrado que sea es un objeto, algo lejano, con cierto hálito de inhumanidad, que está más allá de todo y que no es tratado con la sensibilidad (positiva o negativa) con que se trata a un individuo. La despersonalización es una actitud cargada de frialdad.

(...) cuando les vieron así unidos en un todo perfecto, adivinaron por primera vez muchos mitos antiguos, y comprendieron al cabo para qué era buena la mujer. (Cansinos Assens, 2013: 229)

Para este objeto, que no obstante interactúa en el devenir de los hombres, la lejanía del amor carnal, depositada en la mujer que no goza de la santidad, concede una falsa seguridad: el mundo está lleno de peligros para toda fémina considerada «pura». La tentación invade las calles.

(...) tu vida es bella aquí, sin besos en las castas mejillas, solo entibiadas por el calor de la cera sacra que se consume... Y la dulce muchacha, fija sus ojos, llenos de fe, en la imagen del santo patrono, ingenuo y pastoril... (Cansinos Assens, 1918: 29)

Pero es que el mundo que nos presenta Cansinos es el mundo de la deformidad, del agravio a la moral, el mundo de la injusticia y del sexo que, al fin y al cabo, es el único mundo del hombre, el único posible. La pureza y la virginidad son admiradas, pero esconden una esclavitud antinatural, una belleza idílica que no es humana del todo, sino en su apreciación.

Por tu belleza cándida, las niñas llegan a ti con confianza... ¿y no ves cómo te miran cual si fueras una monja consagrada a Dios? (Cansinos Assens, 1918: 43) 
Lo que la liturgia hace al invocar el mito de la belleza no es sino apoderarse de esta realidad que en nada se parece al ideal. El único modo de aproximar al hombre a la fe es el de encauzar su imperfección en una empatía del pecado, asumiendo que Dios no transforma, pero perdona, que no hay un mejor mundo en éste, sino en el más allá, y que el ideal, la pureza de la mujer es un valor que, entendido por el hombre, redime y consuela y puede hallarse en la maternidad y el matrimonio. De esta manera, la institución religiosa, en su afán por medrar, consigue cambiar ciertos estigmas asociados a la mujer en el pasado y que no servían sino para mostrar un lado negativo de la misma. Negatividad, por consiguiente, que queda sedimentada en el hecho cultural, y no desaparece, pero que se reduce a ciertos aspectos de su conducta, coincidentes con el modelo de mujer más liberal y más sexualmente explícita. El propio autor es capaz de advertirlo desde su posición crítica.

Para los profetas y los redactores del Antiguo Testamento, la mujer representa la impureza, la abominación, el pecado sexual, y por eso suelen acompañarla, en sus alegorías, de la serpiente o el dragón. (Cansinos Assens, 1925: 27)

Entonces, se pasa de un mito estigmatizado a un mito valorizado, que sirve de armazón al modelo de la familia católica pero que, a su vez, no destierra la imagen que se ha inculcado en la cultura vernácula del sexo libre asociado al pecado, y éste a la mujer pecadora. Pero, claro, el sexo es también una herramienta de magnificación de la figura de Dios, puesto que el hombre está hecho a su imagen y semejanza y necesita buscarse en él, que es el camino del otro. La concepción, en el ámbito de la familia, es un intento sucesivo de engendrar la belleza divina, su geist, en el hijo venidero. Los hijos son una bendición del creador, son una fuente de vida que limpia las impurezas del sexo y lo convierten en una unión mística. De modo que no se trata del sexo o la libidinosidad del hombre, lo que causa una perturbación en la liturgia, sino la finalidad del mismo: toda condición hedonista, todo placer por el placer o todo gusto estético está asociado al pecado, y no a la maravilla que supone crear una nueva vida, como ejemplo seguido en Cristo. De ahí que el esteticismo modernista, todo forma y placer de la forma, sea visto como una desviación, como una ociosidad inútil que se enfrenta a un modo de arte representativo de la sociedad. El modernismo, entonces, no transmite unos valores aprehendidos en la cultura dominante $\mathrm{y}$, por lo tanto, es un arte secundario y pecador, que concuerda con los valores de negatividad arraigados en el ideal católico. La redención sólo llega a través de la aceptación vehiculada de los valores, al igual que en el sexo. Es decir, en el reconocimiento de los cánones artísticos y el lenguaje casticista.

El politeísmo y la poligamia, las dos formas de multiplicidad, las dos promiscuidades execrables, terminarán al mismo tiempo en la unidad del Cordero. El Cordero, la víctima inocente, será el lazo de unión entre las razas. Eva habrá quebrantado el poder del dragón, y en adelante el instinto sexual dejará de ser causa de pecado, esto es, de concupiscencias y crímenes. Las madres concebirán hijos a semejanza del Justo, del Cordero. (Cansinos Assens, 1925: 35)

Empero, admitamos que en la historia de la Iglesia, la mujer es vista como un elemento disonante, del que se podría prescindir pero que ha de encontrar un encaje en la filosofía general. Como ser despreciado, sólo puede recibir ciertos beneficios del modelo general de la filosofía católica, que se va adaptando a los momentos históricos y a las necesidades de la Iglesia. Siempre y en todo momento, es un objeto manipulado por la teatralidad del mensaje católico, y en la modernidad, sin embargo, el arte le ofrece la oportunidad de un desarrollo individual 
y colectivo que, al menos, como objeto de arte, está inyectado de probidad. Por ello, puede desechar el complejo de culpa que la Biblia le atribuye, su sello como origen del pecado, del mal y la desviación del hombre, al que se califica como víctima inocente de su perfidia.

El misoginismo de la Biblia, que quisiera anular a la hembra como culpable de la desventura universal, y que inspira ese horror al amor, simbolizado en la figura de la Gran Ramera, transige aquí con la necesidad de esa escala mística del cuerpo de la hembra para subir otra vez hasta Dios mediante la cadena de las generaciones, rehabilitando en la persona de Sara, la calumniada, el principio femenino. (Cansinos Assens, 1925: 51)

Y la Iglesia vende la idea de que la mujer ha de ser liberada de esa carga — que ella misma le ha impuesto- a través de la divinidad y la pureza. En realidad, la mujer tiene que soportar una carga mayor que la original para poder ser aceptada por la institución religiosa, lo que implica una esclavitud mayor que la del sexo que, según el catolicismo, es un mal del pecado en sí mismo si no recibe la gratitud de Dios en su consagración del acto reproductivo. La Iglesia ha condenado históricamente a la mujer, incluso al elevarla a los altares; es más, seguramente ésa es una de sus mayores condenas pues, de todos modos, jamás la religión ha considerado la libertad del individuo desde ninguno de sus aspectos. La mujer no necesita que nadie la libere, y por eso las meretrices de Cansinos no se sienten perdidas en virtud de su sexualidad, sino por la tristeza que les provoca su exclusión, de la que ellas no son responsables.

Cristo simboliza así el rescate del sexo, la emancipación del amor, la liberación de la pesadilla erótica. Las criaturas todas se aman puramente en Cristo, se poseen en él santamente. (Cansinos Assens, 1925: 61)

Incluso ese papel que le asigna la Iglesia: la virginidad, la pureza de la madre, la esposa, la belleza de la fe, representa el espacio de salvación de la humanidad que puede ser construido desde otros puntos de vista alejados de la liturgia. La mujer es un espacio onírico y un refugio de los males, algo que se desprende de su innata naturaleza protectora más que de ningún símbolo artificial. Ese espacio de recogimiento, lo es también de reflexión íntima, de pregunta, que invita a la relación con uno mismo y con el otro. La comunicación con el cuerpo de la mujer, ya dijimos, es un punto de referencia para el reconocimiento de las debilidades del hombre: un espacio, también, de exclusividad, aislamiento, individualidad, exploración. El amor y el sexo como formas de catarsis del ser en el teatro del ser, descubiertas las miserias de la razón y liberadas las tensiones del dolor y el placer. El sexo es una llamada de la sangre ineludible y también la mujer concentra los rasgos más llamativos de su presentación. El espacio que supone la mujer, arraigado culturalmente, se identifica, asimismo, con una palabra heredada que es base constructora de civilizaciones. En el caso de la mujer en el mundo judío - algo que compete a la literatura cansiniana — es la palabra la que crea el tipo ideal de fémina, no correspondido tampoco con la realidad cotidiana sino con el mito. Si Occidente supone la realidad del día a día, Israel es el ideal. La mujer judía, en su magnificencia, es la Israel acosada por el destino y es el bien del pueblo judío. La palabra es ella. Aquí sí que hay una gran diferencia con el modelo católico, ya que la mujer católica es sólo un rasgo representativo de la santidad como un todo completo, mientras que la mujer judía aglutina la palabra, la tierra, el espacio y la moral, con lo que su categorización supone, en sí, el conocimiento y la verdad de Dios. 
(...) un hombre que sentía el amor como el poeta de El cantar de los cantares, y no encontraba la Sulamita capaz de amarle con la pasión de la regia pastora, de salir a buscarle en la noche, saltando por los collados, macerándose los pies en las espinas del camino y afrontando los dardos de los guardianes de las puertas! ¡Su pasión no podía ser correspondida por las mujeres occidentales que le rodeaban! Astutas y egoístas, advertían éstas en seguida su oriental exaltación, el poder idolátrico con que le fascinaban, y complacíanse en probar hasta qué punto podía su corazón ser vulnerado. (Cansinos Assens, 2011: 135)

Y como espacio de reconciliación con la humanidad que es, la mujer es el hogar. En el envite de la miseria, la paz que representa la mujer contrasta con el desamor y el desencanto del hombre que se hunde sin amparo.

La casa se hizo más fea, más destartalada, más fría, desde que le faltaba aquel rescoldo de amor. La dulce sonrisa de la criada, que se llevó Dios al paraíso de los humildes, encantaba antes la casa con una apariencia de hogar dichoso y de madre viva. Pero ahora la casa se había hecho odiosa y triste. El pobre padre, noble y triste fantasma, era muy poco visto de los niños; la casa sucia y fría lo echaba, y el pobre señor, arruinado, se iba con su noble aire antiguo a aumentar las sombras de la noche y a beber en la tibiera de las tabernas sus licores mortales. (Cansinos Assens, 2011d: 171)

\section{SEXO Y MITO}

El sexo también es una huida del mundo, una vía de escape, un escondite. Y así se reivindica en el espacio reflexivo de la feminidad, espejo identificativo de las necesidades que el hombre arrostra.

Porque así es de discreta esta casa, en esta calle sin reverberos, donde las estrellas brillan lejanas como sobre el mar, que los que salen de ella y vuelven a la luz de las grandes vías pueden creer que todo ha sido un sueño. (Cansinos Assens, 2013: 34)

También, a través del sexo, el hombre tiene la oportunidad de regresar al seno materno, espacio insondable de felicidad y protección. La infancia, el origen de la existencia, tienen un componente sexual muy fuerte en la personalidad que se desarrolla, posteriormente, en la búsqueda incesante del camino de vuelta y que, en el ámbito de la acción amorosa pone en evidencia las debilidades del abandono que, en su día, supuso la desprotección de la madre. El hombre es un eterno destetado que llora por ello. La posesión del objeto sexual, así, se erige en un dramático complejo de Edipo.

¡Oh, amada: eres enorme e inagotable, y quisiera encerrarme dentro de ti, como los hijos que de ti han salido! (Cansinos Assens, 2013: 149)

Aquí se observan particulares interconexiones entre la posesión carnal y la ocupación de la matriz femenina. Vagina y matriz son conductos que se dirigen al objeto femenino, a su espiritualidad, pues lo que se atrapa de él es su amalgama sentimental, su capacidad amatoria y no su actividad erótica, que es una consecuencia estética y, poco menos, que formal. Por ende, cuando hablamos de sexo nos referimos a la espiritualidad del mismo, en una complejidad que abarca diferentes y sutiles ámbitos de la posibilidad de amar a otro ser, cuya 
conexión se produce, no en el momento del coito -o no sólo ahí- sino a través de la relación de fuerzas íntimas de los individuos y sus necesidades. El deseo es tan profundo, que no existe otro modo mejor de llenar los vacíos personales que llegando a ser residente del cuerpo deseado, dentro de él, físicamente ocupando su globalidad. En el fondo, el sexo denota un esfuerzo inútil, ya que nadie puede acaparar el ser en su totalidad y estamos condenados a la convivencia con la nada, con los vacíos que nos genera la conciencia. Toda existencia es conciencia, y toda conciencia es nada. Aunque siempre podemos seguir manteniendo la ilusión de que la referencia futura, o la figura de perfección nos hagan de faro del devenir.

-Sí, Maruja —-murmuró convencido—, tú eres la verdad... (Cansinos Assens, 1923a: 4)

Descendiendo al comportamiento más mundano de los individuos, la pasión erótica es una cualidad que la literatura entronca con la juventud de los personajes, donde se produce un germen de sexualidad que, en el caso de las mujeres, alude a una llamada de la naturaleza. Y como corifeos del instinto, la mujer ejerce de evocador de la pasión y latencia de los sentimientos dormidos, pero nunca ausentes, encargando una responsabilidad del llamado sexo fuerte, que se ve en la obligación natural de corresponder a la satisfacción demandada. Por tanto, en la función tradicional de los sexos, el instinto corresponde a la mujer y la concreción, al hombre.

Eres varón y eres una ofrenda para las mujeres; la flaqueza femenina debe reposar sobre ti como reposa el cielo sobre la firme tierra; y como los montes, que levantan su espalda, así debes soportar tu carga de placeres heroicamente, sin lanzar un suspiro. (Cansinos Assens, 2011c: 31-32)

Y así, el hombre también es esclavo de una función social de su sexo, que le exige soportar el dolor físico que conlleva el esfuerzo de cumplir con ella, una entrega que convoca al disfrute pero también a la aceptación de las reglas. En el éxito de su participación se juega el prestigio de su virilidad.

(...) tú eres el que debe sonreír alegremente con los riñones quebrantados. (Cansinos Assens, 2011c: 32)

La pasión erótica es un juego de coincidencias y atracciones, de afinidades y sorpresas, que pertenece, en el pensamiento colectivo, a una fábula de la sutileza, de lo que no se dice pero se intuye, de la palabra esquiva, de la ociosidad del verbo en la estética comprensiva de un logos intencionadamente perverso. El actor, entonces, puede comparar a la mujer sencilla con animales, exagerando su condición rural, sensual y libre, ignorante e inocente.

(...) porque ella era de un país del Norte donde las mujeres tan sólo abrían sus brazos ampliamente cuando el amor cosquilleaba sus cuellos y las dejaba débiles y postradas sobre la tierra verdecida como los bueyes acariciados entre un cuerno y el otro. (Cansinos Assens, 2013: 30)

Un juego fabulado que corresponde a la naturaleza irracional del erotismo, algo carnal, primario, que forma parte de una comunicación primitiva.

Tú sientes que tu placer se me comunica y me penetra, que no estás solo en el goce, sino que yo lo comparto contigo; yo soy tu hembra y tú eres mi macho, Xan, y esto es más fuerte que todo. (Cansinos Assens, 1923a: 5) 
Para el tradicionalismo, no hay lugar para el placer si no está tipificado en los gustos canonizados. A esto responden la bohemia y todo tipo de satanismos, enfrentados con el poder establecido y rebelados en todo lo que signifique, de algún modo, depravación y vicio. Los modernismos elevan a santidad algunos de estos comportamientos, tolerando lo que de violento o degradante impliquen, como formas de humanidad soterradas que reflejan parte de nuestra naturaleza. Algunos autores ven en el amor la oportunidad propicia de la mujer, como naturaleza dominadora, para acarrear al hombre una situación de víctima de sus deseos. La secular perfidia femenina, junto a su inteligencia superior para el mal, la convierte en un ser despreciable, a la vez que temible y enormemente atractivo. Lo que se condena, realmente, no es a la mujer en sí sino al mal que la identifica, puesto que el hombre se siente encadenado a la debilidad que le suponen determinados deseos y anhelos, que no le permiten avanzar en su construcción personal. El lastre de los vacíos siempre aparece como un obstáculo a la razón y a la consecución del desarrollo más absoluto. Sin embargo, de no existir estos vacíos es probable que no existiese el arte e intuimos que la nueva ideología da buena fe de ello, al mostrar que la negatividad del ser humano deviene en una estética compleja, bella e interesante.

Una dulzura excesiva, manifiesta en sus ojos garzos, ingenuos e infantiles, una irresistible necesidad de amar, habíale entregado indefenso a los designios soberbios de las mujeres, y hecho de él un trofeo fácil para adornar sus sueños. Siempre fue defraudado en el amor, siempre fue burlado, como si sus amadas presintiesen desde el primer instante que podían hacer de él una víctima. (Cansinos Assens, 2011: 134)

¿Y por qué, entonces, la literatura se empeña en mostrar a la mujer como un objeto en manos del hombre, afianzando la virilidad como culmen social? En el caso de Las luminarias de Janucá, Cansinos también hace uso de este tipismo literario. Sin embargo, en su amplia novelística breve el personaje femenino casi nunca depende de la posición del varón; más bien, es éste el que tiene una deuda con la mujer que lo protege y lo ampara y, sin la cual, su destino estaría escrito antes de tiempo. Incluso en su desgracia personal y su soledad, la mujer posee recursos que el hombre parece haber desterrado de su función social y haber traspasado al ámbito de la feminidad, como si éstos denigraran su condición histórica y su ideario de fortaleza y superación. Tal vez, porque es más fácil trasladar la propia debilidad al otro, limpiando la imagen del símbolo sexual. Así, es curioso que se relacionen el alcohol y la mujer como emblemas de perdición, ya que uno parece ser la compensación por la ausencia del otro y, en tal caso, el alcohol tiene un matiz de consolación que la mujer no parece desprender, en las ocasiones en que el varón no consigue materializar sus deseos. La venganza por la propia debilidad que generan las pasiones mundanas se vierte así sobre el ser que contiene los valores oníricos. Toda la historia parece una venganza contra las mujeres por poseer todo lo que el hombre añora. En La novia escamoteada, es él el que se quiere librar de Ella, y Ella no entiende el mundo en que vive, parecen preguntarse: ¿por qué se confunde el auténtico amor con la locura? Al marcharse de su lado para siempre, acaba sumiendo al protagonista en una profunda duda. Si el amor existe, por lo tanto, pero no se materializa, si se mantiene en la reflexión, en el escepticismo existencial, el esquema de conexiones que el hombre y la mujer trazan se acaba desmoronando. La pasión exige su destrucción a través del sexo, para ser completado y para generar esa decepcionante pregunta final, que es la confirmación de que todo deseo no puede llegar a saciarse, de que es incompleto y que la búsqueda 
no finaliza en el acto carnal, sino que se ha de buscar a sí misma hasta realizarse, lo que implica un camino infinito. Es por esto que es fácil la relación entre divinidad y sexo, puesto que la conexión que implica con el ser contiene la renuncia a una respuesta finalista, y ése es el auténtico conocimiento que destila, su verdad. Y la posesión, al no completarse, genera un desasosiego que se trasluce en la violencia del acto sexual que, en algunos casos, identifica el orgasmo con la vileza del acto machista, toda vez que el objeto ya no tiene independencia alguna y es un juguete en manos del amante.

Volvía a ser la viviente, a la que yo más de una vez, en insensato arranque de celos, había deseado ver muerta para que fuera en la muerte únicamente mía (...) (Cansinos Assens, 2011b: 112)

En ese momento, perdido el respeto por la persona ante la elevación del objeto sexual, el amor por la muerta, personaje de la novela La que tornó de la muerte, se torna rencor por la viva: así, la posesión infame del objeto ha cosificado una ensoñación y ha alejado de sí el amor por una persona, cuyo espíritu ha desaparecido a ojos del deseo, y se ha congelado en un mito onírico que ya no posee sino las condiciones de idealización que el hombre había imaginado en él. El protagonista, ciego y loco de amor, renuncia al rostro que amaba para no perder la sensación de supremo éxtasis a la que había llegado, y, de este modo, deja atrás toda conciencia de las cosas.

Mi piedad primera, mi piedad absoluta de embalsamador para la pobre muerta mía, habíase trocado en crueldad y rencor. (Cansinos Assens, 2011b: 113)

Así que el amor, en su estado de supraconciencia, ha modificado la percepción de realidad que el protagonista tiene, constatando que el mito ha intervenido en el orden de las cosas trasponiendo los valores que estabilizaban el edificio de los papeles sociales. Aunque para el resto de ciudadanos, este protagonista seguirá siendo un excluido, un enfermo de amor, un hombre digno de piedad, en su conciencia no habitará más sino que el de la exaltación y la conservación de la tumultuosa verdad que le ha sido revelada y, en la práctica, toda sociedad conocida habrá sido borrada de su existencia. La razón convencional ataja el problema poniéndole etiquetas: locura, extravagancia, delirio... pero existen motivos, como vemos, mucho más complejos que no indican falta de razón sino, tal vez, elementos de desconexión emocional que el sexo es capaz de detonar. Esto, por supuesto, no sería posible de no ser porque el hombre es un niño indefenso ante el poder sexual de la mujer. Y, en mi opinión, se siente cómodo con esa doble razón: por un lado, la posesión del objeto le facilita su vuelta al seno materno, al estado ideal de protección de la infancia, a la teta y, por otro, compensa esa conciencia de debilidad, de necesidad imperiosa, con la intervención de la fuerza física, al relacionar ciertos modos de agresividad y violencia con el acto sexual, como hemos venido diciendo. De esta forma, el hombre, a través de la posesión, recupera su terruño original, el de la única mujer que amó sinceramente: su madre.

(...) se encontró de pronto sereno e ingenuo como cuando era niño y jugaba con amiguitas algo mayores. (Cansinos Assens, 2013: 9)

La percepción de la violencia en la sexualidad, el erotismo agresivo de los hombres, consigue construir metáforas de gran calado literario. Así, en Las dos amigas, nuestro autor describe las miradas varoniles como «puntas de cigarros»(Cansinos Assens, 1923c: 1). El 
fuego que abrasa es el calor necesario y, sin embargo, pernicioso. Por consiguiente, a la mujer no le basta con ser una amante fuerte y dominadora, fuente de calor y vida, también, ya que es innegable su dependencia. Se reafirma en la relación amorosa donde, al margen de toda sociedad, puede controlar el cauce de pasiones del que ella es la protagonista, aun a sabiendas de que necesita ser amada tanto como él. No obstante, el juego teatral ha de mantener la liturgia, puesto que así lo requiere el equilibrio de las cosas mundanas y el gobierno de los sentidos que parecemos querer darnos.

Xan, te acoges a mí como a un refugio, porque sabes que yo soy para ti la verdad. Te guareces en mi pecho como un niño (...) eres un niño grande: pero por eso necesitabas una mujer como yo, que me ha criado poco menos que sola desde pequeña y no le tengo miedo a nada, y soy toda una mujer. (Cansinos Assens, 1923a: 6)

Es el propio Cansinos el que ve que el sexo está condicionado por el egoísmo, por un solipsismo que impide la auténtica entrega del alma y los sentimientos. Y es el acto sexual, en realidad, el que provoca tal situación, puesto que el amor es una aspiración que persigue la comunicación por encima de la posesión, una respuesta convencional y directa a una pregunta que implica la personalidad del que la realiza.

La ternura indeterminada y abstracta en que el individuo tocado por la gracia del amor quisiera comulgar con la Humanidad entera redúcese a un sentimiento egoísta y exclusivo, en cuanto interviene el sexo, declarando las intenciones ocultas de la especie. La cópula es un acto solitario; los amantes buscan por instinto la soledad y las tinieblas, no porque tengan la intuición de cometer un acto malo, como pensaba Schopenhauer, sino porque la peculiaridad del amor es elegir por modo exclusivo, y su elección implica un desdén absoluto y una afrenta para todas las demás criaturas no señalados con su dardo. (Cansinos Assens, 1925: 7)

¿Qué ocurre después de entregar el cuerpo, hay algo que se pierde definitivamente? ¿Trata el sexo del acabamiento de una cualidad, de agotar la fruta, de usar la belleza hasta su agotamiento? Tal vez el autor percibe que, en la celosa intuición femenina de que ha de proteger «su bien» para seguir manteniendo la atracción del varón, a la mujer le va en juego algo más que su juventud o su posibilidad de alcanzar el matrimonio; hay algo natural, parecido a una virginidad mental, que ha de seguir funcionando o, de lo contrario, su feminidad acabará convertida en un desecho.

(...) como una criada suya (...) indigna de sentir celos ni de considerarse rival de las demás mujeres, todas más jóvenes ya para el amor que ella, la pobre criatura exprimida y desangrada en el tálamo (...) (Cansinos Assens, 1924: 1)

No es, por consiguiente, difícil de imaginar la asociación de ideas en la que acaba confluyendo la teoría cansiniana del amor y el sexo, ya que una vez que el cuerpo ha sido usado hasta la saciedad de la pasión, permanezca o no el amor romántico, la angustia invadirá el deseo, y la tierra hollada ya no tendrá el brillo de la imaginación y la idea original, sino el desperdicio grosero de lo orgánico. Puede que la concepción de la muerte como fin del sexo sea, en definitiva, un argumento consecuente con la aseveración grotesca de la carne y la firme e inválida respuesta que ésta devuelve al hombre. Además, el camino del pensamiento siempre lleva al individuo a los límites de su existencia, por lo que la nada es consustancial a toda verdad contenida en el ser. ¿Para qué despreciar lo que somos, por feo que resulte? Si 
el sexo invalida el sentido de la vitalidad, una vez consumado, sólo queda, para librarnos de esa sensación de muerte, una nueva repetición del acto, una renovación de la pregunta que, cíclicamente, nos conducirá a la certeza trágica de la existencia.

\section{REFERENCIAS BIBLIOGRÁFICAS}

\section{Artículos}

Conde Guerri, M. ${ }^{a}$ José: Rafael Cansinos Assens en la novela corta, León, Universidad de León, Versión PDF (disponible en Internet), págs. 29-30-31.

Vicente García, Luis Miguel: La reflexión sobre la condición femenina en la obra de Rafael Cansinos Assens. Lo que hubiera respondido Emilia Pardo Bazán (disponible en Internet), pág. 51.

\section{Obras de Rafael Cansinos Assens}

Cansinos Assens, Rafael, 1916: El sacrificio del más joven, Madrid, La novela para todos, Año I, Núm. XII, 8 de Junio, pág. 197.

- (1918): El eterno milagro, Madrid, Biblioteca «Patria” de obras premiadas. Tomo CXLVII, págs. 29-43.

- (1922): La amada fúnebre, Madrid, La Novela Corta. Núm. 320. Año VII. 28 de Enero.

- (1923a): Alma carne, Madrid, La Novela Corta. Núm. 393. Año VIII, págs. 4-5-6.

- (1923b): La pobre reina de Chipre, Madrid, La Novela Corta. Núm. 374. Año VIII. 3 de Febrero, pág. 12.

- (1924): Maternidad última, Madrid, La Novela Corta. Núm. 459. Año IX. 20 de Septiembre, pág. 1

- (1925): Los valores eróticos en las religiones. De Eros a Cristo, Madrid, Casa Editorial V. H. Sanz Calleja, págs. 7-27-35-51-61.

- (1930): Los valores eróticos en las religiones. El amor en el Cantar de los cantares, Madrid, Mundo Latino, págs. 23-230.

- (1936): Evolución de los temas literarios, Santiago de Chile, Ediciones Ercilla, pág. 17

- (2011): Las luminarias de Janucá, Madrid, Arca Ediciones, págs. 134-135.

- (2011b): La que tornó de la muerte (1918), Madrid, Biblioteca Misterio. Edición facsímil, págs. $112-113$.

- (2011c): El secreto de la sabiduría (1918), Madrid, Biblioteca Hispania. Parábola. Edición facsímil, págs. 31-32-76.

- (2011d): En la tierra florida (1920), Madrid, Editorial Mundo Latino. Edición facsímil, págs. 1026-37-80-84-93-122-161-171-204.

- (2013): Las cuatro gracias (narraciones de amor) (1918), Madrid, Editorial Mundo Latino. Edición facsímil, págs. 9-30-34-149-229.

\section{Estudios generales}

Augé, Marc: Los no lugares. Espacios del anonimato. Una antropología de la sobremodernidad, Traducción de Margarita Mizraji, Barcelona, Gedisa, 2008.

AzAm, Gilbert: El modernismo desde dentro, Barcelona, Anthropos, 1989.

Beauvoir, Simone DE: El segundo sexo, Madrid, Cátedra, 1998. 
Clark, Suzanne: Women writers and the revolution of the world, Indianapolis, Indiana University Press, 1991.

CAmPs, Victoria: El siglo de las mujeres, Madrid, Cátedra, 2003.

De Rougemont, Denis: El amor y occidente, Traducción de Antoni Vicens, Barcelona, Círculo de Lectores, 1978.

Eagleton, Terry: La estética como ideología, Traducción de Germán Cano y Jorge Cano, Madrid, Editorial Trotta, 2011.

MARTínez PÉRsico, Marisa: La gloria y la memoria. El Ultraísmo iberoamericano «suivant les traces» de Rafael Cansinos Assens, París, BOD, 2012.

Mead, George H.: Mind, Self, and Society, Chicago and London, The University Chicago Press, 1972.

Menke, Christoph: La soberanía del arte. La experiencia estética según Adorno y Derrida, Traducción de Ricardo Sánchez Ortiz de Urbina, Madrid, Visor, 1997.

Ricoeur, Paul: La metáfora viva, Traducción de Agustín Neira, Madrid, Editorial Trotta, 2001.

SÁnchez Dueñas, Blas: De la invisibilidad a la creación. Oralidad, concepción teórica y material preceptivo en la producción literaria femenina hasta el siglo XVIII, Salamanca, Editorial Renacimiento, 2008. 